\title{
STABILITY OF BINARY COMPLEXES OF Pb(II), Cd(II) AND Hg(II) WITH MALEIC ACID IN TX100-WATER MIXTURES
}

\author{
Malla Ramanaiah ${ }^{1,2}$, S. Goutham $\mathrm{Sri}^{1}$ and B.B.V. Sailaja ${ }^{2 *}$ \\ ${ }^{1}$ Department of Chemistry, Aditya Institute of Technology and Management, Tekkali-532201, \\ India \\ ${ }^{2}$ Department of Inorganic \& Analytical Chemistry, Andhra University, Visakhapatnam-530 003, \\ India
}

(Received May 7, 2013; revised August 22, 2014)

\begin{abstract}
Binary complexes of maleic acid with toxic metal ions such as $\mathrm{Pb}$ (II), $\mathrm{Cd}(\mathrm{II})$ and $\mathrm{Hg}(\mathrm{II})$ have been studied in $0.0-2.5 \% \mathrm{v} / \mathrm{v}$ tritonX-100 (TX100) - water media at $303 \mathrm{~K}$ at an ionic strength of $0.16 \mathrm{M}$. The active forms of the ligand are $\mathrm{LH}_{2}, \mathrm{LH}^{-}$and $\mathrm{L}^{2-}$. The derived 'best fit' chemical speciation models are based on crystallographic R-factors, $\chi^{2}$ and Skewness and Kurtosis factors. The predominant species formed are of the type $\mathrm{ML}_{2}, \mathrm{ML}_{2} \mathrm{H}$ and $\mathrm{ML}_{3}$. The trend in variation of complex stability constants with change in the mole fraction of the medium is explained on the basis of prevailing electrostatic and non-electrostatic forces. The species distribution as a function of $\mathrm{pH}$ at different compositions of TX100-water mixtures and plausible speciation equilibria are presented and discussed.
\end{abstract}

KEY WORDS: Maleic acid, TritonX-100, Toxic metal ions, Mole fraction, Binary complexes

\section{INTRODUCTION}

The toxicity, bio-availability, bio-degradability, bio-accumulation, persistence, mobility, solubility, extractability and many other critical properties of chemical species depend on their form and nature [1-3]. Speciation analysis or simply 'speciation' is the determination and characterisation of these species. Speciation has gained wide recognition as a major characteristic of inorganic chemistry, since knowledge of the total concentration of an element in a specific medium is often inadequate to explain its properties and function. The term speciation encompasses two connotations 'functional' and 'operational'. This may overlap but are not identical. Functionally we may identify and distinguish between species that are, for example, available to plants or ecotoxic species of an element that are more easily exchangeable in mineral surfaces than others.

The International Union of Pure and Applied Chemistry (IUPAC) [4] has differentiated 'speciation' from 'functionality' by defining speciation as the process yielding evidence of the molecular form of an analyte. However, even if this is the objective of all studies, operationally speciation is determined by the physicochemical properties of the real natural entities. Speciation refers, to the determination of the concentration of various fractions, which are clusters of species having different physicochemical properties and as such are extractable or detectable under specific conditions.

The role of micelles is simple, but vital, resulting in compartmentalization of the energy transfer partners. Additionally the micro-environment created around the micelle favors dissociation of complexes. By binding the metal ions electrostatically to the negatively charged micellar surface, their effective concentration is substantially increased. The concentration of these counter cations in the micellar surface has been estimated [5] to be around $3.0 \mathrm{M}$. A literature survey $[6,7]$ reveals that increased concentration of micellised surfactant leads to the distribution of the reactants over a wide micelle concentration range which leads to reactants dilution in the micellar pseudo phase and decreases the observed rate constants. Micellar effects

*Corresponding author. E-mail: sailaja_bbv@yahoo.co.in 
on reactivity are generally independent of changes in micellar size and shape. The effect of micelles on overall reaction rates and equilibria depends upon the incorporation of solutes into the micellar pseudo phase. Also, the species with lower charge or higher hydrophobicity are stabilized in the micellar pseudo phase. Thus, metal ligand combinations resulting in neutral complexes are favored. It has been demonstrated that water insoluble metal chelates can be solubilised with a micellar solution of non-ionic surfactant such as TX100. This solubilisation technique is frequently utilized in analytical procedures [8]. Since TX100 is a non-ionic surfactant, it is expected to destabilize charged species in aqueous solutions. This paper reports a speciation study of binary complexes of $\mathrm{Pb}(\mathrm{II}), \mathrm{Cd}(\mathrm{II})$ and $\mathrm{Hg}(\mathrm{II})$ with maleic acid using nonionic micelles to stabilize intermediates.

\section{EXPERIMENTAL}

\section{Materials}

Maleic acid (E-Merck, Germany) solution $(0.05 \mathrm{M})$ was prepared in triple-distilled deionised water by maintaining $0.05 \mathrm{M}$ nitric acid concentration to increase the solubility. TX100 (Merck, India) was used as received. $2 \mathrm{M}$ sodium nitrate (Qualigens, India) was prepared to maintain the ionic strength in the titrand. $0.1 \mathrm{M}^{1}$ aqueous solutions of $\mathrm{Pb}(\mathrm{II}), \mathrm{Cd}(\mathrm{II})$ and $0.05 \mathrm{M}$ aqueous solution of $\mathrm{Hg}(\mathrm{II})$ nitrates were prepared by dissolving G.R. Grade (E-Merck, Germany) salts in triple-distilled water maintaining $0.05 \mathrm{M}$ nitric acid to suppress the hydrolysis of metal salts. All the solutions were standardized by standard methods. To assess errors in concentration determinations, the data were subjected to analysis of variance of one way classification [9]. The strengths of alkali and mineral acid were determined using the Gran plot method [10, 11].

\section{Instrumentation}

The titrimetric data were obtained using an ELICO (Model LI-120) pH meter (readability 0.01), which was calibrated with $0.05 \mathrm{M}$ potassium hydrogen phthalate in acidic region and $0.01 \mathrm{M}$ borax solution in basic region. The glass electrode was equilibrated in a well-stirred TX100water mixture containing the inert electrolyte. All the titrations were carried out in a medium containing varying concentrations of TX100-water mixtures $(0.0-2.5 \% \mathrm{v} / \mathrm{v})$ by maintaining an ionic strength of $0.16 \mathrm{M}$ with sodium nitrate at $303.0 \pm 0.1 \mathrm{~K}$. The effect of variation in asymmetry potential, liquid junction potential, activity coefficient, sodium ion error and dissolved carbon dioxide on the response of the glass electrode was accounted for by a correction factor $[12,13]$.

\section{Analytical procedures}

For the determination of stability constants of metal-ligand binary species, initially titrations of strong acid with alkali were carried out at regular intervals to check whether complete equilibration was achieved. Then the calomel electrode was refilled with TX-water mixture of equivalent composition as that of the titrand. In each of the titrations, the titrand consisted of approximately $1 \mathrm{mmol}$ mineral acid in a total volume of $50 \mathrm{~mL}$. Titrations with different ratios $(1: 2.5,1: 3.75$ and $1: 5.0$ in the case of $\mathrm{Pb}(\mathrm{II})$ and $\mathrm{Cd}(\mathrm{II})$ and 1:7.5, 1:8.5 and 1:10.0 in the case of $\mathrm{Hg}(\mathrm{II})$ ) of metal-to-ligand were carried out with $0.4 \mathrm{M}$ sodium hydroxide. Other experimental details are as reported previously $[14,15]$.

\section{Modeling strategy}

The computer program SCPHD [16] was used to calculate the correction factor. By using the $\mathrm{pH}$-metric titration data, the binary stability constants were calculated with the computer 
program MINIQUAD75 [17], which exploit the advantage of the constrained least-squares method in the initial refinement and reliable convergence of Marquardt algorithm. During the refinement of binary systems, the correction factor and the protonation constants of maleic acid were fixed. The variation of stability constants with the mole fraction of the medium was investigated on electrostatic and non-electrostatic forces on the basis of solute-solute and solutesolvent interactions.

\section{RESULTS AND DISCUSSION}

The results of the final 'best-fit' models that reveal the stoichiometry of the complex species and their overall formation constants along with some of the associated statistical parameters are given in Table 1 . Very low-standard deviation in overall stability constants $(\log \beta)$ signifies the precision of these data. The small values of $U_{\text {corr }}$ (sum of squares of deviations in concentrations of ingredients at all experimental points) corrected for degrees of freedom, small values of mean, standard deviation and mean deviation for the systems studied are validated by the residual analysis $[18,19]$.

Table 1. Parameters of 'best fit' models of $\mathrm{Pb}(\mathrm{II}), \mathrm{Cd}(\mathrm{II})$ and $\mathrm{Hg}$ (II) - maleic acid complexes in TX100water mixtures.

\begin{tabular}{|c|c|c|c|c|c|c|c|c|c|c|}
\hline \multirow{2}{*}{$\begin{array}{l}\% \mathrm{v} / \mathrm{v} \\
\text { TX100 }\end{array}$} & \multicolumn{3}{|c|}{$\log \beta_{\operatorname{mlh}}(\mathrm{SD})$} & \multirow[t]{2}{*}{ pH-range } & \multirow[t]{2}{*}{$\mathrm{NP}$} & \multirow[t]{2}{*}{$\mathrm{U}_{\text {corr }}$} & \multirow[t]{2}{*}{$\chi^{2}$} & \multirow[t]{2}{*}{ Skewness } & \multirow[t]{2}{*}{ Kurtosis } & \multirow[t]{2}{*}{ R-factor } \\
\hline & $\mathrm{ML}_{2}$ & $\mathrm{ML}_{2} \mathrm{H}$ & $\mathrm{ML}_{3}$ & & & & & & & \\
\hline \multicolumn{11}{|c|}{$\mathrm{Pb}$ (II) } \\
\hline 0.0 & $6.65(25)$ & 11.61(27) & $10.15(23)$ & $2.8-7.7$ & 41 & 22.11 & 116.41 & 4.11 & 20.90 & \begin{tabular}{|l|}
0.0498 \\
\end{tabular} \\
\hline 0.5 & $7.49(20)$ & $12.29(24)$ & $10.60(24)$ & $2.8-6.6$ & 19 & 1.25 & 20.33 & 3.59 & 19.23 & \begin{tabular}{|l|}
0.0466 \\
\end{tabular} \\
\hline 1.0 & $7.40(25)$ & $12.68(24)$ & $10.26(25)$ & $3.8-6.2$ & 19 & 28.12 & 22.02 & -1.54 & 5.28 & \begin{tabular}{|l|}
0.0592 \\
\end{tabular} \\
\hline 1.5 & $7.29(13)$ & $12.56(14)$ & $10.63(13)$ & $3.8-6.2$ & 26 & 0.43 & 3.23 & 0.52 & 2.98 & \begin{tabular}{|l|}
0.0174 \\
\end{tabular} \\
\hline 2.0 & $7.47(22)$ & 12.31(25) & $10.56(24)$ & $3.8-6.2$ & 28 & 18.80 & 3.62 & 0.49 & 4.16 & 0.0466 \\
\hline 2.5 & $7.65(13)$ & $12.43(26)$ & $10.75(29)$ & $4.0-6.0$ & 20 & 4.71 & 12.00 & 0.31 & 4.40 & \begin{tabular}{|l|}
0.0244 \\
\end{tabular} \\
\hline \multicolumn{11}{|c|}{$\mathrm{Cd}$ (II) } \\
\hline 0.0 & $6.76(18)$ & $11.73(24)$ & $10.32(12)$ & $4.0-7.2$ & 24 & 3.18 & 5.11 & 0.26 & 3.14 & \begin{tabular}{|l|}
0.0152 \\
\end{tabular} \\
\hline 0.5 & $6.90(23)$ & $12.26(26)$ & $10.25(25)$ & $4.6-6.8$ & 20 & 7.06 & 2.93 & -0.38 & 2.89 & \begin{tabular}{|l|}
0.0303 \\
\end{tabular} \\
\hline 1.0 & $6.46(23)$ & $12.19(22)$ & $9.80(20)$ & $4.0-7.2$ & 26 & 4.78 & 19.23 & 1.39 & 4.38 & 0.0235 \\
\hline 1.5 & $6.68(09)$ & $11.92(15)$ & $9.81(11)$ & $4.1-7.2$ & 28 & 1.20 & 14.29 & 0.95 & 4.54 & \begin{tabular}{|l|}
0.0130 \\
\end{tabular} \\
\hline 2.0 & $6.61(14)$ & $\begin{array}{l}11.99(19) \\
\end{array}$ & $9.80(14)$ & $4.1-7.2$ & 28 & 2.00 & 8.76 & 0.93 & 3.90 & \begin{tabular}{|l|}
0.0169 \\
\end{tabular} \\
\hline 2.5 & $6.64(14)$ & $11.86(17)$ & $10.20(08)$ & $4.1-7.0$ & 26 & 0.87 & 6.10 & 1.55 & 3.32 & 0.0112 \\
\hline \multicolumn{11}{|c|}{$\mathrm{Hg}$ (II) } \\
\hline 0.0 & $6.93(26)$ & $12.75(25)$ & $9.35(29)$ & $4.2-6.4$ & 21 & 7.22 & 3.92 & 1.14 & 5.11 & \begin{tabular}{|l|}
0.0291 \\
\end{tabular} \\
\hline 0.5 & $6.64(23)$ & $12.11(25)$ & $9.32(25)$ & $3.6-5.8$ & 19 & 11.87 & 4.05 & 0.33 & 3.95 & \begin{tabular}{|l|}
0.0343 \\
\end{tabular} \\
\hline 1.0 & $6.55(05)$ & $12.65(03)$ & $9.37(14)$ & $2.2-5.8$ & 23 & 1.50 & 9.49 & 0.29 & 4.17 & \begin{tabular}{|l|}
0.0138 \\
\end{tabular} \\
\hline 1.5 & $6.62(20)$ & 12.31(19) & $9.45(26)$ & $3.6-6.4$ & 26 & 3.91 & 4.67 & 0.48 & 2.91 & \begin{tabular}{|l|}
0.0234 \\
\end{tabular} \\
\hline 2.0 & $6.60(17)$ & $12.32(18)$ & $9.53(21)$ & $3.6-6.4$ & 24 & 2.38 & 2.89 & 0.30 & 3.21 & \begin{tabular}{|l|l|}
0.0196 \\
\end{tabular} \\
\hline 2.5 & $6.56(22)$ & $12.58(14)$ & $9.50(27)$ & $3.4-7.0$ & 14 & 0.91 & 7.14 & -0.04 & 2.20 & \begin{tabular}{|l|}
0.0162 \\
\end{tabular} \\
\hline
\end{tabular}

$\mathrm{U}_{\text {corr }}=\mathrm{U} /(\mathrm{NP}-\mathrm{m}) \times 10^{8} ; \mathrm{NP}=$ number of points; $\mathrm{m}=$ number of protonation constants; $\mathrm{SD}=$ standard deviation.

\section{Residual analysis}

In data analysis involving least squares methods, the residuals (the differences between the experimental data and the data simulated based on model parameters) are assumed to follow Gaussian or normal distribution. When the data are fit into the models, the residuals should ideally be equal to zero. If statistical measures of the residuals and the errors assumed in the models are not significantly different from each other, the model is said to be adequate. Further, a model is considered adequate only if the residuals do not show any trend. Respecting the 
hypothesis that the errors are random, the residuals are tested for normal distribution. Such tests are $\chi^{2}$, skewness, kurtosis and R-factor. These statistical parameters show that the 'best-fit' models reveal the metal-ligand species in TX100-water mixtures.

$\chi^{2}$ is a special case of gamma distribution whose probability density function is an asymmetrical function. This distribution measures the probability of residuals forming a part of standard normal distribution with zero mean and unit standard deviation. The kurtosis values in this study indicate that the residuals form a leptokurtic pattern. The values of skewness recorded in Table 1 are between -1.54 and 4.11 for $\mathrm{Pb}(\mathrm{II}),-0.38$ and 1.55 for $\mathrm{Cd}$ (II) and -0.04 and 1.14 for $\mathrm{Hg}(\mathrm{II})$. These data show that the residuals form part of a normal distribution. Hence, the least squares method can be applied to the present data. The sufficiency of the model is further evident from crystallographic $R$-values. These statistical parameters thus show that the 'best-fit' models characterise the metal-ligand species in TX100 media.

\section{Effect of systematic errors on 'best fit' model}

In order to rely upon the 'best-fit' model for critical evaluation and application under varied experimental conditions with different accuracies of data acquisition, an investigation was undertaken by introducing pessimistic errors in the influential parameters such as concentrations of alkali, mineral acid, ligand, metal, $\log \mathrm{F}$ and volume (Table 2).

Table 2. Effect of errors in influential parameters on $\mathrm{Hg}(\mathrm{II})$-maleic acid complex stability constants in $2 \%$ v/v TX100-water mixture.

\begin{tabular}{|c|c|c|c|c|}
\hline \multirow[t]{2}{*}{ Ingredient } & \multirow[t]{2}{*}{$\%$ Error } & \multicolumn{3}{|c|}{$\log \beta_{\operatorname{mlh}}(\mathrm{SD})$} \\
\hline & & $\mathrm{ML}_{2}$ & $\mathrm{ML}_{2} \mathrm{H}$ & $\mathrm{ML}_{3}$ \\
\hline \multirow{5}{*}{ Acid } & 0 & $6.60(17)$ & $12.32(18)$ & $9.53(21)$ \\
\hline & -5 & $10.05(43)$ & $15.56(35)$ & $13.96(34)$ \\
\hline & -2 & $7.53(28)$ & $13.38(27)$ & $11.00(29)$ \\
\hline & +2 & $6.08(05)$ & $11.02(32)$ & Rejected \\
\hline & +5 & $5.06(11)$ & Rejected & Rejected \\
\hline \multirow{4}{*}{ Alkali } & -5 & Rejected & Rejected & Rejected \\
\hline & -2 & $5.83(05)$ & $10.89(35)$ & Rejected \\
\hline & +2 & $7.79(39)$ & $13.68(36)$ & $11.51(37)$ \\
\hline & +5 & $11.89(74)$ & $17.40(45)$ & $16.44(41)$ \\
\hline \multirow{4}{*}{ Ligand } & -5 & $6.94(44)$ & $13.00(22)$ & $10.69(23)$ \\
\hline & -2 & $6.73(24)$ & $12.60(18)$ & $10.02(20)$ \\
\hline & +2 & $6.46(13)$ & $12.00(20)$ & $8.95(29)$ \\
\hline & +5 & $6.21(07)$ & $11.50(21)$ & Rejected \\
\hline \multirow{4}{*}{ Metal } & -5 & $6.62(20)$ & $12.39(18)$ & $9.68(20)$ \\
\hline & -2 & $6.61(18)$ & $12.34(18)$ & $9.59(21)$ \\
\hline & +2 & $6.59(16)$ & $12.29(18)$ & $9.47(22)$ \\
\hline & +5 & $6.57(15)$ & $12.25(18)$ & $9.38(23)$ \\
\hline \multirow{4}{*}{ Volume } & -5 & $6.71(24)$ & $12.57(18)$ & $9.98(20)$ \\
\hline & -2 & $6.72(24)$ & $12.59(18)$ & $10.00(20)$ \\
\hline & +2 & $6.75(24)$ & $12.62(18)$ & $10.04(20)$ \\
\hline & +5 & $6.76(24)$ & $12.63(180$ & $10.06(20)$ \\
\hline \multirow{4}{*}{$\log F$} & -5 & $6.71(23)$ & $12.56(19)$ & $9.92(21)$ \\
\hline & -2 & $6.72(24)$ & $12.59(18)$ & $9.99(20)$ \\
\hline & +2 & $6.73(25)$ & $12.61(18)$ & $10.05(20)$ \\
\hline & +5 & $6.74(26)$ & 12.64(18) & 10.11(19) \\
\hline
\end{tabular}

The order of the components that influence the magnitudes of stability constants due to incorporation of errors is alkali $>$ acid $>$ metal $>$ ligand $>$ total volume $>\log$ F. Some species 
were even rejected when errors were introduced in the concentrations. The rejection of some binary species and increased standard deviations in the stability constants on introduction of errors confirm the suitability of the experimental conditions (concentrations of components) and choice of the best-fit models.

\section{Effect of solvent}

Variations in the magnitudes of formation constants of the complex species formed due to the interaction between metal ions and maleic acid with mole fraction of the surfactants present are shown in Figure 1, which indicates that the stabilities of the complexes varied linearly with mole fraction of the TX100 media. The linearly increased/decreased stability of the complexes with increased surfactant concentration may be due to the increased number of micelles and decreased dielectric constant of the medium. The dielectric constant of the medium has a direct influence on the protonation-deprotonation equilibria [20, 21]. According to Born's equation [22] the energy of electrostatic interactions is related to dielectric constant of the medium and $\log \beta$ versus $n_{x} \times 10^{3}$ (mole fraction of the medium) should be linear.
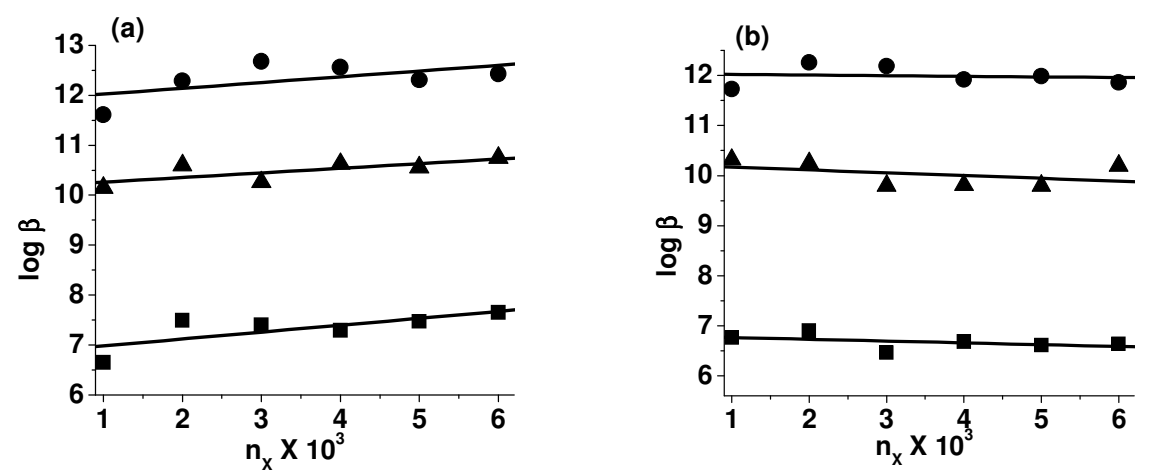

(c)

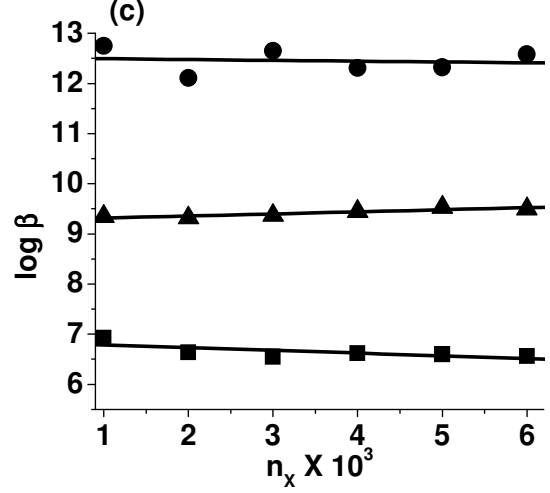

Figure 1. Variation of overall stability constant values of metal-maleic acid complexes with mole fraction $\left(\mathrm{n}_{\mathrm{x}} \times 10^{3}\right)$ of TX100-water mixtures (a) $\mathrm{Pb}(\mathrm{II})$; (b) $\mathrm{Cd}(\mathrm{II})$; (c) $\mathrm{Hg}(\mathrm{II})$; (匹) $\log \beta_{\mathrm{ML} 2} ;(\mathbf{\Delta}) \log \beta_{\mathrm{ML} 3} ;(\bullet) \log \beta_{\mathrm{ML} 2 \mathrm{H}}$. 
The linear variation of $\log \beta$ values of maleic acid complexes of $\mathrm{Pb}$ (II), $\mathrm{Cd}(\mathrm{II})$ and $\mathrm{Hg}$ (II) with mole fraction shows in Figure 1 indicates that the dominance of electrostatic solute-solvent interactions. The anion stabilizing nature of co-solvent, specific solvent-water interactions, charge dispersion and specific interactions of co-solvent with the solute may be responsible for the observed small deviations from a linear relationship. This study is helpful in understanding the co-solvent effect at the molecular level [23-25] and provides useful information in drug design.

\section{Distribution diagrams}

Maleic acid is a bidentate ligand that has two dissociable (carboxyl groups) protons. The different forms of maleic acid are $\mathrm{LH}_{2}, \mathrm{LH}^{-}$, and $\mathrm{L}^{2-}$ in the $\mathrm{pH}$ range $<4.0,2.0-7.0$ and $>6.0$ respectively. Hence, the plausible binary metal-ligand complexes can be predicted from these data. The present investigation reveals the existence of $\mathrm{ML}_{2}, \mathrm{ML}_{2} \mathrm{H}, \mathrm{ML}_{3}$ for $\mathrm{Pb}$ (II), $\mathrm{Cd}$ (II) and $\mathrm{Hg}(\mathrm{II})$. The formation of various maleic acid complex species is shown in the following equilibria.

\begin{tabular}{|c|c|c|}
\hline $\mathrm{M}(\mathrm{II})+\mathrm{LH}_{2}$ & - & $\mathrm{MLH}^{+}+\mathrm{H}^{+}$ \\
\hline $\mathrm{MLH}^{+}$ & 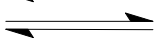 & $\mathrm{ML}+\mathrm{H}^{+}$ \\
\hline $\mathrm{M}(\mathrm{II})+\mathrm{LH}_{2}$ & $=$ & $\mathrm{ML}+2 \mathrm{H}^{+}$ \\
\hline $\mathrm{M}(\mathrm{II})+2 \mathrm{LH}_{2}$ & - & $\mathrm{ML}_{2} \mathrm{H}_{2}+2 \mathrm{H}^{+}$ \\
\hline $\mathrm{MLH}^{+}+\mathrm{LH}_{2}$ & - & $\mathrm{ML}_{2} \mathrm{H}_{2}+\mathrm{H}^{+}$ \\
\hline $\mathrm{ML}_{2} \mathrm{H}_{2}$ & $=$ & $\mathrm{ML}_{2} \mathrm{H}^{-}+\mathrm{H}^{+}$ \\
\hline $\mathrm{MLH}^{+}+\mathrm{LH}^{-}$ & $=$ & $\mathrm{ML}_{2} \mathrm{H}^{-}+\mathrm{H}^{+}$ \\
\hline $\mathrm{ML}+\mathrm{LH}_{2}$ & $=$ & $\mathrm{ML}_{2} \mathrm{H}^{-}+\mathrm{H}^{+}$ \\
\hline $\mathrm{ML}_{2} \mathrm{H}^{-}$ & 二 & $\mathrm{ML}_{2}^{2-}+\mathrm{H}^{+}$ \\
\hline $\mathrm{ML}+\mathrm{LH}^{-}$ & - & $\mathrm{ML}_{2}{ }^{2-}+\mathrm{H}^{+}$ \\
\hline $\mathrm{ML}_{2}^{2-}+\mathrm{LH}^{-}$ & 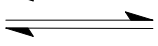 & $\mathrm{ML}_{3}^{4-}+\mathrm{H}^{+}$ \\
\hline $\mathrm{M}(\mathrm{II})+3 \mathrm{LH}_{2}$ & $=$ & $\mathrm{ML}_{3} \mathrm{H}_{3}^{-}+3 \mathrm{H}^{+}$ \\
\hline $\mathrm{MLH}^{+}+2 \mathrm{LH}_{2}$ & 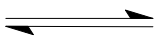 & $\mathrm{ML}_{3} \mathrm{H}_{3}^{-}+2 \mathrm{H}^{+}$ \\
\hline $\mathrm{ML}_{3} \mathrm{H}_{3}^{-}$ & $=$ & $\mathrm{ML}_{3} \mathrm{H}_{2}{ }^{2-}+\mathrm{H}^{+}$ \\
\hline $\mathrm{ML}+2 \mathrm{LH}_{2}$ & $=$ & $\mathrm{ML}_{3} \mathrm{H}_{2}{ }^{2-}+2 \mathrm{H}^{-}$ \\
\hline $\mathrm{ML}_{3} \mathrm{H}_{2}{ }^{2-}$ & - & $\mathrm{ML}_{3} \mathrm{H}^{3-}+\mathrm{H}^{+}$ \\
\hline $\mathrm{ML}_{3} \mathrm{H}^{3-}$ & $=$ & $\mathrm{ML}_{3}^{4-}+\mathrm{H}^{+}$ \\
\hline $\mathrm{M}(\mathrm{II})+2 \mathrm{LH}_{2}$ & $\bar{F}$ & $\mathrm{ML}_{2} \mathrm{H}^{-}+3 \mathrm{H}^{+}$ \\
\hline $\mathrm{M}(\mathrm{II})+2 \mathrm{LH}_{2}$ & 7 & $\mathrm{ML}_{2}^{2-}+4 \mathrm{H}^{+}$ \\
\hline $\mathrm{M}(\mathrm{II})+3 \mathrm{LH}_{2}$ & - & $\mathrm{ML}_{3} \mathrm{H}_{2}{ }^{2-}+4 \mathrm{H}$ \\
\hline $\mathrm{M}(\mathrm{II})+3 \mathrm{LH}_{2}$ & - & $\mathrm{ML}_{3} \mathrm{H}^{3-}+5 \mathrm{H}^{+}$ \\
\hline $\mathrm{M}(\mathrm{II})+3 \mathrm{LH}_{2}$ & - & $\mathrm{ML}_{3}^{4-}+6 \mathrm{H}^{+}$ \\
\hline $\mathrm{ML}_{2} \mathrm{H}_{2}$ & - & $\mathrm{ML}_{2}^{2-}+2 \mathrm{H}^{+}$ \\
\hline $\mathrm{ML}_{3} \mathrm{H}_{3}^{-}$ & $\bar{\eta}$ & $\mathrm{ML}_{3} \mathrm{H}^{3-}+2 \mathrm{H}^{+}$ \\
\hline $\mathrm{ML}_{3} \mathrm{H}_{3}^{-}$ & 7 & $\mathrm{ML}_{3}{ }^{4-}+3 \mathrm{H}^{+}$ \\
\hline
\end{tabular}

The species $\mathrm{ML}_{2} \mathrm{H}_{2}, \mathrm{ML}_{3} \mathrm{H}_{3}{ }^{-}, \mathrm{ML}_{3} \mathrm{H}_{2}{ }^{2-}$ could not be detected in the present study probably because they are formed at very low $\mathrm{pH}$. Some typical distribution diagrams in TX100-water mixtures are shown in Figure 2. They indicate that the binary complexes of $\mathrm{Pb}(\mathrm{II}), \mathrm{Cd}(\mathrm{II})$ and $\mathrm{Hg}$ (II) are formed in the $\mathrm{pH}$ range 3.0-7.0. The species $\mathrm{ML}_{2} \mathrm{H}, \mathrm{ML}_{2}, \mathrm{ML}_{3}$ are formed in the $\mathrm{pH}$ range of 3.0-6.5. $\mathrm{ML}_{2} \mathrm{H}$ is formed at lower $\mathrm{pH}$ with higher percentage [Equilibria (6), (7), (8) and (18)]. $\mathrm{ML}_{2}, \mathrm{ML}_{3}$ are simultaneously formed with the increasing $\mathrm{pH}$. Successive deprotonation of $\mathrm{ML}_{2} \mathrm{H}$ forms $\mathrm{ML}_{2}$ beyond a $\mathrm{pH}$ 6.0. The percentage of the $\mathrm{ML}_{3}$ species increases with increasing $\mathrm{pH}$ up to 7 . The concentration of $\mathrm{ML}_{2} \mathrm{H}$ species decreased, while the 
concentration of $\mathrm{ML}_{2}$ and $\mathrm{ML}_{3}$ increased in the $\mathrm{pH}$ range 4.5-6.5 [Equilibria (9), (10) and (11)]. $\mathrm{ML}_{3}$ formed at higher $\mathrm{pH}$ with high percentage [Equilibria (11), (17), (22) and (25)].
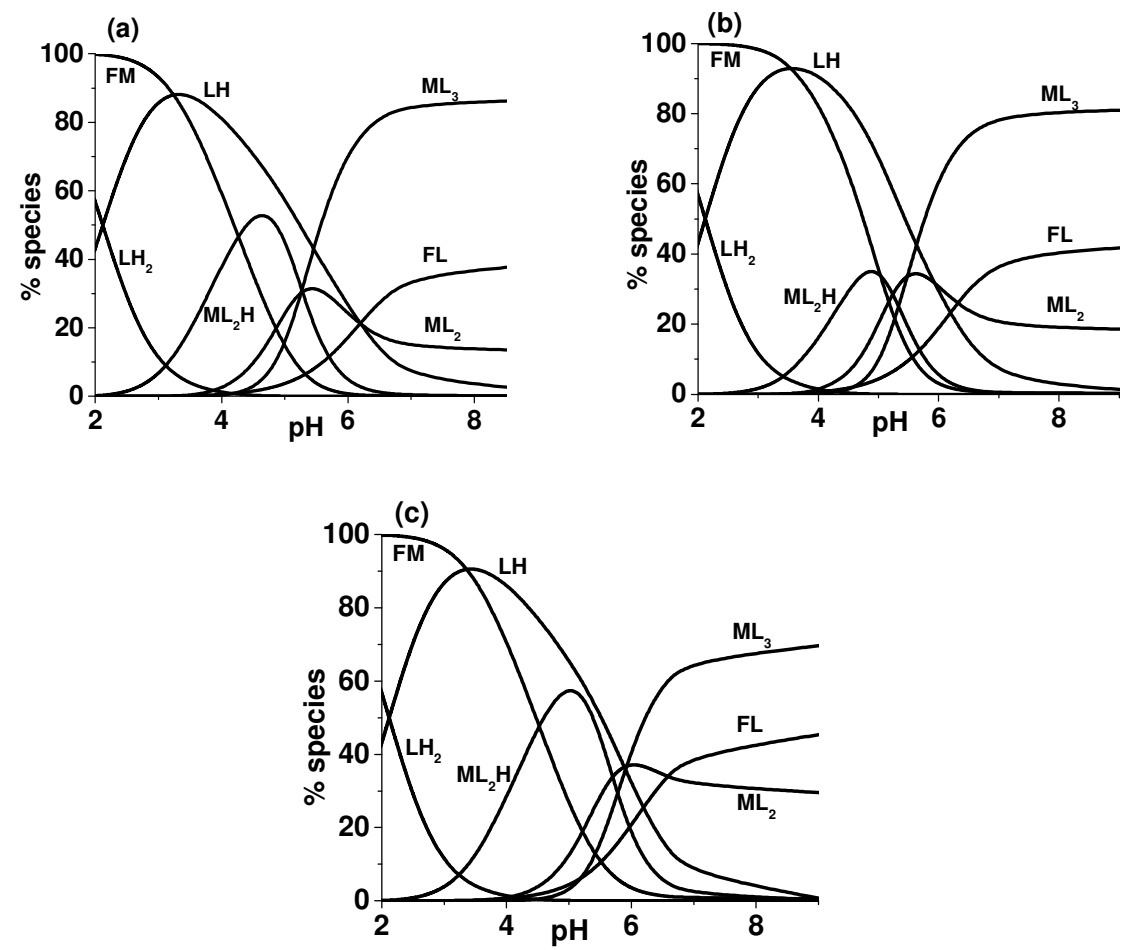

Figure 2. Distribution diagrams of binary complexes of maleic acid in $1.5 \% \mathrm{v} / \mathrm{v}$ TX100-water mixture: (a) $\mathrm{Pb}$ (II), (b) $\mathrm{Cd}(\mathrm{II})$ and (c) $\mathrm{Hg}$ (II).

Structures of complexes

Maleic acid acts as a bidentate ligand by using its two oxygen donor sites and the chelation results in highly stable seven membered rings (Figure 3). Octahedral structures are proposed for the complexes of all the metal ions studied. The VSEPR theory suggests that $\mathrm{Pb}$ (II), $\mathrm{Cd}$ (II) and $\mathrm{Hg}$ (II) complexes should be octahedral because there are six donor electron pairs, which is consistent with the structures proposed in Figure 3. 

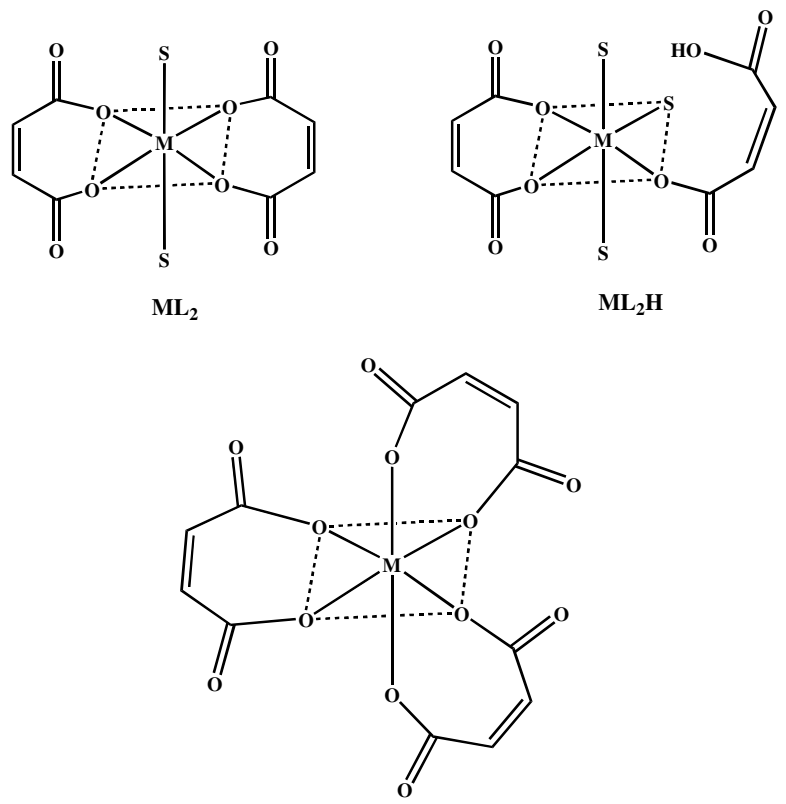

$\mathrm{ML}_{3}$

Figure 3. Structure of maleic acid complexes ( $\mathrm{S}$ is either solvent or water molecules).

\section{CONCLUSION}

The following conclusions have been drawn from the modeling studies of the speciation of binary complexes of $\mathrm{Pb}(\mathrm{II}), \mathrm{Cd}(\mathrm{II})$ and $\mathrm{Hg}(\mathrm{II})$ with maleic acid in $\mathrm{TX} 100$-water mixtures. Maleic acid forms both protonated and unprotonated complexes over a $\mathrm{pH}$ range of 3.0-7.0. The binary species formed by the interaction of maleic acid with metals are $\mathrm{PbL}_{2}, \mathrm{PbL}_{2} \mathrm{H}, \mathrm{PbL}_{3}$, $\mathrm{CdL}_{2}, \mathrm{CdL}_{2} \mathrm{H}, \mathrm{CdL}_{3}, \mathrm{HgL}_{2}, \mathrm{HgL}_{2} \mathrm{H}$ and $\mathrm{HgL}_{3}$. The linear variation of stability constants as a function of mole fraction of the medium indicates the dominance of electrostatic forces over non-electrostatic forces. Some species are stabilized due to electrostatic interactions and some are destabilized due to a decreased dielectric constant. The order of components influencing the magnitudes of stability constants due to incorporation of errors in their concentrations is alkali $>$ acid $>$ ligand $>$ metal $>$ total volume $>\log \mathrm{F}$.

\section{REFERENCES}

1. Florence, T.M. Analyst 1986, 111, 489.

2. Scoullos, M.J.; Pavlidou, A.S. Croat. Chem. Acta 1997, 70, 289.

3. Lores, E.; Pennock, J. Chemosphere 1998, 37, 861.

4. Scoullos, M.J; Pavlidou, A.S. Glob. Nes. 2000, 2, 255.

5. Mukherjee, P. J. Phys. Chem. 1962, 66, 943.

6. James, A.D.; Robinson, B.H. J. Chem. Soc. Faraday I 1978, 74, 10.

7. Mukerjee, P.; Mysels, K.J. Critical Micellar Concentrations of Aqueous Surfactant Systems, National Bureau of Standards: Washington; 1971. 
Stability of complexes of $\mathrm{Pb}(\mathrm{II}), \mathrm{Cd}(\mathrm{II})$ and $\mathrm{Hg}(\mathrm{II})$ with maleic acid in TX100-water mixtures 391

8. Hinze, W.L. Solution Chemistry of Surfactants, Vol. 1, Plenum Press: New York; 1979.

9. Rao, R.S.; Rao, G.N. Computer Applications in Chemistry, Himalaya Publishing House: Mumbai, India; 2005

10. Gran, G. Analyst 1952, 77, 661.

11. Gran, G. Anal. Chim. Acta 1988, 206, 111.

12. Ramanaiah, M; Goutham Sri, S; Sailaja, B.B.V. Chem. Spec. Bioavail. 2013, 25, 285.

13. Ramanaiah, M; Sailaja, B.B.V. Chem. Spec. Bioavail. 2014, 26, 119.

14. Rama Raju, B.; Santhee Devi, K.V.; Rao, G.N. Chinese J. Inorg. Chem. 2012, 28, 785.

15. Ramanaiah, M; Sailaja, B.B.V. J. Indian Chem. Soc. 2014, 91, 1011.

16. Rao, G.N. Complex equilibria of biological importance in aquo organic media-computer augmented modeling studies, Ph.D. thesis, Andhra University, Visakhapatnam, India, 1989.

17. Gans, P.; Sabatini, A.; Vacca, A. Inorg. Chim. Acta 1976, 18, 237.

18. Ramanaiah, M; Goutham Sri, S; Sailaja, B.B.V. J. Indian Chem. Soc. 2014, 91, 351.

19. Ramanaiah, M; Sailaja, B.B.V. J. Indian Chem. Soc. 2014, 91, 639.

20. Bunton, C.A.; Romsted, L.S.; Supulveda, L. J. Phys. Chem. 1980, 84, 2611.

21. Chaimovich, H.; Politi, M.J.; Bonilha, J.B.S.; Quina, F.H. J. Phys. Chem. 1979, 83, 1951.

22. Born, M. Z. Phys. 1920, $1,45$.

23. Obata, Y.; Takayama, K.; Maitani, Y.; Machida, Y. Int. J. Pharm. 1993, 89, 191.

24. Takahashi, K.; Tamagawa, S.; Katagi, T.; Yoshitomi, H.; Kamada, A.; Rytting, J.H.; Nishihata, T.; Mizuno, N. Chem. Pharm. Bull. 1991, 39, 154.

25. Gungor, S.; Bergisadi, N. Pharmazie 2004, 59, 39. 